\title{
Entre las autoridades, la agricultura comercial y las comunidades locales: conflictos durante la construcción del embalse Puclaro (1996-2001)
}

\author{
Sebastián Castillo Castillo ${ }^{1}$ \\ Recibido: 12 de septiembre de 2015 - Aceptado: 10 de noviembre de 2015
}

\begin{abstract}
Resumen
Desde la implementación del sistema económico neoliberal en Chile, la agroindustria comercial de exportación se ha extendido en zonas limitadas de agua, requiriéndose embalses que han perjudicado a comunidades. Este trabajo se adscribe en la historia ambiental, rama de la disciplina histórica que devela la relación dinámica entre el hombre y el medioambiente que ha sido habitado, explotado y significado. La presente entrega analiza el conflicto entre autoridades estatales y pobladores afectados por procesos de erradicación y relocalización, en el Valle del Elqui durante la construcción del Embalse Puclaro. Este conflicto se evidenció en los contradictorios discursos realizados por autoridades y dirigentes vecinales, en las dispares formas de acción colectiva de los pobladores, y en las compensaciones recibidas y graves problemas que sufrieron los afectados. De esta manera, la investigación demuestra que la agricultura sustentada por embalses, genera efectos negativos e irreversibles sobre comunidades que pagan "el costo del progreso".
\end{abstract}

Palabras clave: Embalse Puclaro, Valle del Elqui, erradicación forzada, Gualliguaica, La Polvada

\section{Among authorities, commercial agriculture and local communities: conflicts during the construction of Puclaro dam (1996-2001)}

\begin{abstract}
Since the implementation of the neoliberal economic system in Chile, commercial export agribusiness has spread in limited water areas, requiring dams that have damaged communities. This work is included in the environmental history, a branch of the historical discipline that reveals the dynamic relationship between humans and the environment that has been occupied, exploited and meant. This
\end{abstract}


paper examines the conflict between State authorities and residents affected by eradication and relocation processes at Elqui Valley during the construction of Puclaro Dam. This conflict was evident in the contradictory speeches made by officials and neighborhood leaders, in the disparate forms of collective action of affected people, compensations received and the serious problems suffered by the affected. Thus, research shows that agriculture sustained by dams generates negative and irreversible effects on communities that pay "the cost of progress."

Keywords: Puclaro Dam, Elqui Valley, forced eradication, Gualliguaica, La Polvada

\section{Entre as autoridades, a agricultura comercial e as comunidades locais: conflitos durante a construção de embalse Puclaro (1996-2001)}

\section{Resumo}

Desde a execução do sistema econômico neoliberal no Chile, a agroindústria comercial de exportação tem-se estendido em áreas limitadas de água, requerendo-se de represas que prejudicam as comunidades. Este trabalho é atribuído na história ambiental, ramo da disciplina histórica que revela a relação dinâmica entre o homem e o meio ambiente que tem sido habitado, explorado e significado. 0 artigo analisa o conflito entre as autoridades estatais e as populações afetadas pelos processos de erradicação e de recolocação no Vale do Elqui durante a construção da represa Puclaro. Este conflito evidenciou-se nos discursos contraditórios realizados pelas autoridades e dirigentes vicinais, nas formas díspares de ação coletiva dos moradores e nas compensações recebidas e graves problemas que sofreram os afetados. Desta forma, a pesquisa mostra que a agricultura sustentada pela represa, gera efeitos negativos e irreversíveis sobre as comunidades que pagam "o custo do progresso".

Palavras-chave: Represa Puclaro, Valle do Elqui, erradicação forçada, Gualliguaica, La Polvada.

Chile ha desarrollado un rubro agrícola comercial exportador en zonas como la Región de Coquimbo, actividad limitada por la disponibilidad de recursos hídricos gestionados por embalses. La agroindustria ha sido una ocupación fundamental para el devenir económico de Chile, impulsada por el modelo económico neoliberal implementado durante el Gobierno Militar a partir de la década de 1970, sistema que ha estimulado la llegada de inversiones nacionales y extranjeras al mundo rural chileno. La agricultura comercial se ha desarrollado en las zonas del Norte Chico y Central ${ }^{2}$ chilenas, siendo la Región de Coquimbo y el Valle del Elqui polos agrícolas para 
cultivar frutos rentables como la uva exportada a mercados del Hemisferio Norte. Sin embargo, la principal limitación en estas zonas ha sido la escasez de agua, dadas las características pluviales y geográficas que presentan estos lugares aptos para desarrollar negocios agrícolas. Para solventar la limitada disponibilidad de recursos hídricos se han construido embalses que, a priori, han garantizado una gestión eficaz, intensiva y segura del agua, aumentando cualitativa y cuantitativamente la productividad agrícola.

El caso de estudio de esta investigación es el Embalse Puclaro, anhelada obra de irrigación que traería el ansiado progreso agrícola a la región, pero que impactó a la comunidad local durante su proceso de construcción. Dicha obra es estudiada por el impacto que provocó sobre la comunidad local establecida en la zona donde éste se construyó y almacenó el agua, sufriendo transformaciones en sus modos de vida por la erradicación y relocalización forzadas. Los embalses han sido necesarios para mantener el desarrollo de la agroindustria comercial; sin embargo, éstos crean externalidades negativas sobre poblaciones locales que no poseen recursos económicos, políticos ni humanos suficientes para impedir sus construcciones. En consecuencia, algunas preguntas surgen sobre el Embalse Puclaro: ¿existió un discurso único sobre éste durante su proceso de construcción? ¿De qué manera impactó su construcción a la sociedad local compuesta por los poblados instalados en la zona donde esta obra se construyó y almacenó el agua? ¿El período de construcción del Puclaro estuvo exento de controversias y conflictos? ¿Cuáles fueron las respuestas de la sociedad local ante los inconvenientes generados por la edificación? ¿Estas respuestas influyeron en las decisiones de autoridades sobre el devenir de los afectados? ¿Cuáles fueron las compensaciones que recibieron los afectados y los problemas que experimentaron en este período?

El presente trabajo está adscrito a la historia ambiental, campo investigativo de la disciplina histórica que ha adquirido sentido a partir de la década de 1990 y que estudia cambios ambientales, ideas y representaciones de la naturaleza y las respuestas sociales y culturales de cada grupo humano hacia los ecosistemas que transforman (Gallini, 2009: 93). En este escrito, se plantea que es pertinente conocer tanto este estudio de caso como otros trabajos sobre historia ambiental por dos motivos: primero, comprender la figura del Hombre como agente transformador de un espacio dinámico, dados intereses económicos, culturales, sociales e incluso políticos suscitados por grupos humanos a lo largo del pasado. Mientras que el segundo es otorgar relevancia historiográfica al medioambiente en cuanto tal, espacio que rara vez ha sido entendido como actor histórico importante por derecho propio; por el contrario, ha sido estudiado como mero telón de fondo o escenario en el que transcurrieron los acontecimientos (Gallini, 2009: 97). Por otra parte, es pertinente que historiadores, geógrafos y profesores de Historia y Geografía conozcan lo ocurrido en la construcción del Puclaro, ya que es un caso regional que ilustra aspectos fundamentales de 
nuestro país como su histórica vocación exportadora de recursos naturales sin un valor agregado, su inserción en los mercados internacionales en el marco de una globalización mundial, su dependencia de recursos hídricos, cada vez más evidente a causa de necesidades humanas y períodos de sequía que golpean a Chile, y las tensiones entre actores sociales por la apropiación de territorio nacional y explotación -en muchos casos, sobreexplotación- de materias primas extraídas desde ecosistemas terrestres y marinos.

Con el objetivo de ofrecer una contextualización temática precisa, la expansión de la agricultura comercial en el marco del modelo económico neoliberal ha sido tratada en trabajos historiográficos circunscritos a diversas áreas de estudio, destacándose el impacto de factores transformadores sobre el campo chileno. Luz Cereceda resaltó la nueva orientación del Estado a partir de 1973, el cual inició cambios en el sector rural a través de mecanismos como la liberalización del mercado de tierra y de los precios agrícolas, y la apertura al mercado internacional. Estas medidas tendieron a formar y fortalecer un sector empresarial eficiente que aprovechase las ventajas comparativas del país en el exterior, respetándose la iniciativa privada y la libre competencia (Cereceda, 1980: 99-103). Para Sergio Gómez y Jorge Echeñique, las altas tasas de ganancias y acumulación atrajeron capitales de conglomerados nacionales y multinacionales, fortaleciéndose un subsector empresarial agrícola moderno, articulado con el resto de los sectores económicos (Gómez y Echeñique, 1988: 273). Como contrapartida, surgió un rubro campesino con escasa producción agrícola, el cual combinó las faenas agrarias con otras actividades económicas y usó fuerza de trabajo familiar (Gómez y Echeñique, 1988: 205). Según Roberto Santana, dos sectores destacaron en este nuevo escenario: uno volcado hacia la exportación y otro que no pudo superar fácilmente su situación de fragilidad. Por otra parte, "la agricultura para la exportación se situó fundamentalmente en Chile Central, teniendo como eje principal la producción de frutas, complementada con lo que aporta el Norte Chico, gracias a la expansión de la capacidad de riego" que transformó esta zona de valles semiáridos en "la tierra de los parronales", siendo las plantaciones de uva de mesa el eje de concentración de los terrenos agrícolas (Santana, 2006: 315).

El impacto de la expansión agrícola sobre los recursos hídricos ha sido tratado con menor énfasis, constituyendo un aspecto que requiere profundización. Roberto Santana argumentó que el aumento de la capacidad de riego en la agricultura se debió fundamentalmente a una política de Estado que fomentó los proyectos de construcción de sistemas de embalses en la década de 1980, y a nuevas disposiciones legales que favorecieron las inversiones en cultivos exportables altamente consumidores de agua (Santana, 2006: 316). Sin embargo, según Warnick Murray, la expansión de la actividad agrícola intensiva presionó el medio ambiente local y regional, especialmente en el Norte Chico, lo que generó severos desabastecimientos de agua y degradación del medioambiente, entre otros problemas (Murray, 1999: 96). Estas compresio- 
nes sobre el ambiente local son relatadas por Viviana Benz, quien expuso la compleja situación del poblado de Gualliguaica antes de ser sumergido por las aguas del Embalse Puclaro. La autora planteó algunas condiciones mínimas que debían ser garantizadas como compensación de la erradicación que las personas sufrirían (Benz, 1997).

\section{Embalse Puclaro, seguro de garantía para el riego del Elqui}

El Embalse Puclaro es un proyecto de origen estatal localizado en la Región de Coquimbo, con un período de construcción que se prolongó por tres años, administrado por la Junta de Vigilancia del Río Elqui desde que éste entró en funcionamiento ${ }^{3}$. Este sistema de obras hidráulicas está ubicado en la cuenca natural del Valle del Elqui a 50 kilómetros al oriente de la ciudad de La Serena, en un área donde prima un clima de tipo mediterráneo árido con gran irregularidad de pluviometría anual (Diario El Día, 23-IX-1998). El inicio oficial de las obras fue el 1 de septiembre de 1996, finalizando el 15 de octubre de 1999. Su inauguración fue el 26 de octubre de 1999, encabezada por el Presidente de la República Eduardo Frei Ruiz-Tagle. La construcción estuvo a cargo de la Dirección de Obras Hidráulicas del Ministerio de Obras Públicas, ejecutándola las empresas constructoras Méndez Junior y Diwydag. El proyecto se conformó por una presa de 80 metros de altura y longitud en su coronación de 595 metros, la cual cierra completamente el cauce natural del río Elqui (Diario El Día, 15-V-1999). En el lado sur del embalse se encuentra el lago artificial de una "capacidad total de 200 millones de metros cúbicos, una superficie de 70 hectáreas y 7400 metros de largo" (Comisión Nacional de Riego, 1999: 2). Además de la presa, el embalse está conformado por un muro de contención, un túnel de desvío que transporta el agua, un evacuador de crecidas, y por una capa de material consistente en piedras con el fin de tener una alta resistencia a los movimientos sísmicos (Diario El Día, 26-X-1999). Asimismo, un tramo de 10 kilómetros de la ruta D-41 fue reconstruido en la ladera oriente de la obra, pues la anterior vía pasaba por la zona de construcción y almacenamiento de agua.

El mayor beneficio que trajo el embalse fue el aprovisionamiento seguro de los recursos hídricos, favoreciendo la agricultura del Valle del Elquil ${ }^{4}$ e impulsando

\footnotetext{
La Junta de Vigilancia del Río Elqui y sus afluentes es una organización privada que se encarga de gestionar las aguas del cauce natural del río Elqui, distribuyéndola a quienes poseen los derechos de uso. Si bien el Embalse Puclaro fue un proyecto de origen estatal, el financiamiento de la obra provino de la Dirección de Obras Hidráulicas y de la Junta de Vigilancia del Río Elqui. Una vez que el embalse terminó de construirse, su administración quedó en manos de particulares agrupados en la Junta de Vigilancia del Río Elqui y sus afluentes

$4 \quad$ Es deber destacar que el aprovisionamiento del agua no es el único factor que incide en el desarrollo agrícola regional. También hay otros como las inversiones en estructuras de riego, tecnología y mecanización, fondos de apoyo, entre otros.
} 
la creación de empleos, la estimulación del turismo y la generación de energía eléctrica. El principal bien de la construcción del Puclaro fue el aseguramiento de recursos hídricos, obteniendo "20700 hectáreas una seguridad de riego de un $85 \%$, lo que beneficiaría a 2508 predios de aproximadamente 8 hectáreas cada uno" (Comisión Nacional de Riego, 1999: 2). Con ello, la cantidad total de hectáreas que podían ser regadas aumentó al doble (Diario El Día, 22-II-1999). El Puclaro también incrementó cualitativamente la productividad agrícola porque, según el Seremi de Agricultura Guillermo Machala, se pudo "realizar cultivos de mayor rentabilidad, como es el caso de la uva de exportación, dejando de lado la estacionalidad de las producciones y pudiendo cultivarse distintos productos durante el transcurso del año" (Diario El Día, 22-II-1999). Asimismo, el Puclaro fue una fuente de empleo al requerirse alrededor de 39100 horas/mes para su construcción (Diario El Día, 2-IX-1996). Incluso, este embalse fue pensado como atractivo turístico, usando sus aguas para desarrollar actividades náuticas o pesca deportiva, y convirtiendo los sitios aledaños en zonas de camping (Diario El Día, 2-IX-1996). La instalación de una central hidroeléctrica dentro del embalse fue un deseo de la Junta de Vigilancia del Río Elqui, pretensión cumplida el año 2008 cuando ella entró en funcionamiento (El Observatodo, 6-V-2008). En base a lo anterior, el Embalse Puclaro ha impulsado actividades económicas estratégicas tales como la agricultura, el turismo y la generación de energía eléctrica.

En suma, el Embalse Puclaro fue un proyecto estatal localizado en la Región de Coquimbo a 50 kilómetros de la ciudad de La Serena, siendo su construcción ejecutada por empresas constructoras extranjeras, y administrado posteriormente por la Junta de Vigilancia del Río Elqui. Su edificación se extendió desde 1996 hasta 1999, y su inauguración fue encabezada por el Presidente Eduardo Frei Ruiz-Tagle. Dentro de los beneficios que trajo la obra se encuentran el incremento cuantitativo y cualitativo de la productividad agrícola, la generación de empleos durante su construcción, el estímulo del turismo y la generación de energía eléctrica.

\section{La concreción de un anhelo, según la Concertación ${ }^{5}$}

El rol de algunas autoridades estatales durante la construcción del Embalse Puclaro fue clave para resaltar dicho proceso, ya que dos aspectos fueron destacados en los discursos realizados. El primero, fue la serie de beneficios económicos que traería la obra, traducidos en un progreso general para el Valle del Elqui y la Región de Coquimbo. Mientras que el segundo, fue la

La Concertación de Partidos por la Democracia fue una coalición política que estuvo a la cabeza del Poder Ejecutivo entre los años 1990 y 2010. Durante el proceso de construcción del Puclaro, el Presidente de Chile fue Eduardo Frei Ruiz-Tagle. 
gestión de los gobiernos de la Concertación para impulsar la edificación de la obra.

La construcción del Puclaro fue legitimada por algunas autoridades estatales y parlamentarios de la Concertación a través de discursos que enfatizaron la noción de que gracias al embalse llegaría el progreso a la zona, pues se potenciarían actividades como la agricultura y el turismo. En la ceremonia de inicio de la construcción del embalse en 1996, el Diputado Joaquín Palma señaló que "la visita del Presidente Frei a la zona marca el inicio de una nueva gran etapa para los pobladores del Valle del Elqui y, por ende, para todos los agricultores que por años y años han vivido de la voluntad de la madre naturaleza" (Diario El Día, 13-IX-1996). En 1999, el Ministro subrogante de Obras Públicas Juan Carlos Latorre señaló que el Puclaro generaría "una serie de posibilidades de inversión para el sector agroindustrial, que sin duda será una estrategia para el desarrollo de la Cuarta Región" (Diario El Día, 16-V-1999). Para Lombardo Toledo, Director Regional de la Junaeb durante el período investigado, la inauguración del tranque cumplía "un sueño de todos los habitantes del Valle del Elqui y es el resultado de una de las tantas iniciativas del Gobierno de Eduardo Frei" (Diario El Día, 8-X-1999). Tales declaraciones respaldaron la obra, ya que se esperaba que ella potenciara actividades estratégicas para la región como la agricultura y el turismo. Sin embargo, llama la atención que se mencionase que el embalse beneficiaría al Valle del Elqui y a la Región de Coquimbo por completo. Esto último es bastante dudoso, dada la imposibilidad que la obra beneficiase a todas y cada una de las personas de dichas zonas, por lo que apelar al progreso general de la zona se hizo fundamentalmente para resaltar la grandeza de la obra. En otras palabras, aquellas personas con capitales suficientes para invertir en la agricultura fueron los grandes beneficiados con el Puclaro, o sea, pequeños y medianos agricultores y empresarios con inversiones agrícolas destinadas a la exportación. Por lo tanto, generalizar los beneficios de la obra fue hecho con el fin de subrayar el esfuerzo político de las autoridades para su construcción.

El segundo elemento destacado en el discurso oficial es la noción de que la construcción del Embalse Puclaro se debió al esfuerzo de los gobiernos de la Concertación, materializando así un sueño de décadas. Una de las personas involucradas activamente en este proyecto fue el Intendente Renán Fuentealba Moena, quien señaló que la concreción del Puclaro fue "la realización de un sueño esperado desde hace muchos años", siendo "un clamor de 50 a 60 años", donde "todos los candidatos presidenciales o a diputados y senadores prometían en sus discursos que se realizaría el tranque Puclaro, pero nunca se concretó. Hasta que en los últimos años comenzó un trabajo absolutamente planificado, teniendo afortunadamente el pleno apoyo de los presidentes Aylwin y Frei" (Diario El Día, 26-X-1999). El discurso de Fuentealba resaltó la gestión de los gobiernos de la Concertación para concretar una 
obra esperada -en especial la administración de Eduardo Frei-, al mencionar que no se había construido el Puclaro en el pasado. Dado que esta obra fue un proyecto estatal reconocido a nivel regional, ésta sería aprovechada por la Concertación para obtener un importante respaldo ciudadano en las elecciones presidenciales de 1999. El reconocimiento de las autoridades se debió también a los objetivos ambiciosos que debía cumplir la obra, tales como el almacenamiento de agua y el combate de su carencia en tiempos de sequía, y la minimización de los riesgos del negocio agroindustrial por la falta de agua. Por lo tanto, mostrar la construcción del Puclaro como un logro de los gobiernos de la Concertación, permitiría a esta coalición política aumentar su aprobación y respaldo popular de cara a las elecciones venideras. En este contexto emergió la figura de Ricardo Lagos Escobar, quien visitó el avance de las obras del Puclaro como Ministro de Obras Públicas y compitió, posteriormente, en las elecciones presidenciales como candidato de la Concertación.

Ricardo Lagos estableció una relación entre el Embalse Puclaro y las elecciones presidenciales de 1999, al ser el Ministro de Obras Públicas que inspeccionó el avance de los trabajos del embalse y el competidor en dichos comicios nacionales que ganó, obteniendo un alto porcentaje de votos en la Región de Coquimbo. La inauguración e inicio de operaciones del Embalse Puclaro sucedieron en 1999, mismo año en que se efectuaron las elecciones presidenciales. La visita al embalse más destacada de Lagos ocurrió el 1 de mayo 1998, siendo consultado por el Diario El Día sobre su carrera presidencial (Diario El Día, 2-V-1999). La victoria de Lagos en los comicios nacionales se proyectó en la Región de Coquimbo, zona en la que obtuvo el 60,04\% de los votos válidamente emitidos, siendo el mayor porcentaje de votos a nivel nacional ${ }^{6}$. Esto se debió, entre otros tantos aspectos, a la preocupación de las autoridades por destacar el Embalse Puclaro y proyectar a la Concertación como promotora y gestora de una obra que le cambiaría el rostro al Valle del Elqui y a la Región de Coquimbo. Así, los discursos sobre el Puclaro fueron una herramienta valiosa para la Concertación, con el fin de prolongar su administración presidencial por seis años.

En síntesis, dos elementos fueron destacados en los discursos oficiales sobre el Embalse Puclaro: los beneficios económicos que traería la obra, traducidos en un progreso general para la zona; y la gestión hecha por los gobiernos de la Concertación para materializar este anhelo de décadas. Estas declaraciones buscaron aumentar el respaldo de esta coalición política,

6 Datos obtenidos gracias a la información electoral histórica del Servel. Se extrajo la información desde el sitio web: http://historico.servel.cl/ss/site/elecciones_presidenciales_1989_ al_2013.html 
encontrándose en el horizonte las elecciones presidenciales de 1999. Ellas fueron ganadas por Ricardo Lagos Escobar, quien visitó el avance de las obras del Puclaro como Ministro de Obras Públicas y obtuvo el mayor porcentaje nacional de votación en la Región de Coquimbo.

\section{¿Autoridades preocupadas desde el principio por los afectados?}

Luego de exponer los discursos de las autoridades sobre la construcción del Puclaro, cabe preguntarse algunas interrogantes: ¿se recalcó en ellos los avances del proceso de erradicación y relocalización, mostrándolos también como un triunfo de los gobiernos de la Concertación? ¿Hubiese sido negativo para la Concertación que la situación de los afectados fuese tratada en los discursos de las autoridades? ¿Los representantes estatales se preocuparon por aquellos que se vieron afectados por la construcción del embalse?

Las autoridades manifestaron que se preocuparon desde un principio por la situación de las personas erradicadas y relocalizadas por el Puclaro, pese a que, según ellas, aquello no estuviese dentro de sus obligaciones legales. Con motivo de la inauguración del nuevo pueblo de Gualliguaica en el año 2001, el Ministro de Obras Públicas Carlos Cruz expresó que los dirigentes gubernamentales sopesaron los aspectos positivos y negativos del Puclaro, buscando alternativas para mitigar el daño hacia los afectados: "desde un comienzo las autoridades de todos los niveles compartieron la inquietud ciudadana sobre el altísimo impacto social negativo, a pesar del enorme progreso que significa el embalse". Por eso, "junto con el pago de la expropiación de terrenos y edificaciones, se buscó una compensación, la mejor posible, para sus pérdidas inmobiliarias" (Ministerio de Obras Públicas, 2001: 3). Siendo consultado por la situación de Gualliguaica en 1999, Eduardo Bartholin destacó la iniciativa de los gobernantes para crear un nuevo pueblo: "el embalse Puclaro lo comenzamos a construir antes que entrara en vigencia la ley de medioambiente ${ }^{7}$, pero voluntariamente a pedido del entonces mandatario de la República Patricio Aylwin y actual Presidente Eduardo Frei, se comenzó a trabajar en el proyecto de un nuevo pueblo" (Diario El Día, 25-V-1999). Según Bartholin, la reubicación de los afectados no fue pensada una vez iniciadas las obras, sino que desde el Gobierno de Patricio Aylwin (1990-1994) se venía elaborando un plan que mitigara los efectos sociales negativos del Puclaro. Al no estar esta ley aprobada cuando se iniciaron las obras del em-

La ley de medioambiente mencionada por la autoridad nacional fue la Ley 19.300 sobre Bases Generales del Medio Ambiente, que obligaba a considerar la mitigación de impactos negativos derivados de construcciones de gran envergadura. 
balse, no era un deber legal de las autoridades preocuparse del proceso de relocalización de los afectados, pagando solo las indemnizaciones de terrenos y propiedades que serían inundadas por las aguas del embalse. La Seremi de Obras Públicas Ivannia Goles dijo que la reubicación de los poblados "no era obligación legal del Ministerio de Obras Públicas porque la construcción de este embalse estaba a cargo de una empresa privada" (Diario El Día, 26-X-1999); por ende, según ella, los entes privados que edificaron la obra debían ocuparse de los afectados. Ahora bien, ¿la opinión de las autoridades sobre la constante preocupación por el impacto social fue compartida por los pobladores afectados y sus representantes?

Los dirigentes vecinales contradijeron la versión de las autoridades porque, para ellos, no existió un compromiso por la relocalización de los poblados desde el primer momento, no sabiendo dónde, cómo ni cuándo serían reubicados. Para René Arias, director de la Escuela Amelia Barahona de Mujica de Gualliguaica, "se tenía contemplado solamente el pago de subsidios", ya que, inicialmente, "no vinieron las autoridades con un proyecto nuevo [de pueblo], sino que solo con subsidios para las familias y allegados" (René

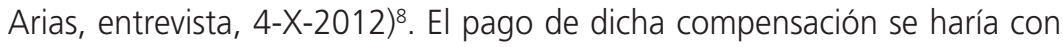
el objetivo que los pobladores recibiesen el dinero y vieran dónde se trasladarían por su propia cuenta. Violeta Cáceres, Presidenta de la Junta de Vecinos de Gualliguaica durante la construcción del Puclaro, señaló que "la gente se sintió mal porque no había mucha información [...] cuando se supo que el embalse se construía, la gente sintió pena porque aún no teníamos un lugar para ser reubicados" (Violeta Cáceres, entrevista, 27-X-2012)9. Las dudas sobre la relocalización son confirmadas al revisar la obra de Viviana Benz sobre el antiguo poblado de Gualliguaica, pues en ella se registra una declaración de Isabel Traslaviña, pobladora con varias interrogantes sobre el proceso: "para mí está claro que el asunto ya no tiene vuelta. El embalse Puclaro va, eso está resuelto. Lo único que nos queda a nosotros es que nos digan, por fin, qué nos van a dar: ¿indemnización buena para que volvamos a construir donde compremos? ¿Un pueblo nuevo, con casas nuevas y buenas? ¿Y cuándo lo sabremos? [...] ¿Ve ese lomaje casi escondido entre los dos montes? Dicen que ahí se levantará el pueblo nuevo. Pero, ¿cómo? ¿Cuándo? ¿Qué planos hay para las casas? ¿Y qué clase de construcciones van a entregar? ¿La escuela será como la de acá, que es casi nueva? ¿Harán

8 René Arias nació en 1958, en Peralillo, Elqui. Él comenzó a trabajar en la Escuela de Gualliguaica a partir de 1992. Participó en el Comité de Refundación de Gualliguaica. Actualmente es el Director de la Escuela Aemlia Barahona de Mujica en Gualliguaica.

9 Violeta Cáceres nació en 1953, viviendo toda su vida en Gualliguaica. Fue Presidenta de la Junta de Vecinos de Gualliguaica entre los años 1995 a 2003, participando activamente como dirigenta durante el proceso de erradicación y relocalización del poblado. Actualmente vive en el nuevo poblado de Gualliguaica, abandonando sus labores de líder vecinal. 
una Iglesia como la de aquí? [...] ¿Han estudiado cómo vive aquí la gente, las familias? ¿Existe un plano que tenga en cuenta todo esto? Hasta aquí nadie lo ha visto" (Benz, 1997: 28-29). Esta declaración refleja la desinformación que existía en la zona, solo sabiéndose que la obra se iba a construir. Junto con la falta de preocupación de las autoridades, hubo otras críticas hacia las autoridades durante la edificación del Puclaro.

El reproche de los dirigentes se debió también a la improvisación, promesas incumplidas y olvido de las autoridades regionales, deteriorándose la imagen sobre ellas. En primer lugar, existió improvisación por parte de los representantes estatales, situación relatada por René Arias cuando el Puclaro cerró sus compuertas. Según explica, el agua "llegó al portón de la escuela y aún no estaba lista arriba [en el pueblo nuevo]. El agua me corrió y solicité ayuda al Municipio para trasladarme al Museo Histórico. Se construyó una escuela provisoria de madera y en el año 2004 estuvo lista la escuela nueva. Todo esto sucedió porque [el proceso] no estaba planificado" (René Arias, entrevista, 4-X-2012). Asimismo, cuando las personas fueron erradicadas del antiguo Gualliguaica, "no hubo nadie que prestara ayuda para trasladar las cosas. Se pudo programar la salida de las personas para ayudar a traerlas porque mucha gente al hombro o en carretas trajo sus cosas, pudiéndose poner a disposición camiones y vehículos, o hacer un plan para hacer un traslado programado" (René Arias, entrevista, 4-X-2012). Tomás Pablo, dirigente del Comité de Allegados de Gualliguaica, contó que las autoridades "se dan cuenta de que no es llegar, construir y recibir la obra (el Puclaro); van dando con el tiempo su brazo a torcer, pero con la intención de engañar, de no dar mucho" (sic) (Tomás Pablo, entrevista, 26-X-2012) ${ }^{10}$. En efecto, las autoridades incurrieron en promesas que no cumplieron, tales como la construcción de la plaza, la Casa Hacienda y el Parque Miradores del Puclaro (Tomás Pablo, entrevista, 26-X-2012). Las negligencias y lo que dejaron de hacer las autoridades durante la construcción del embalse derivó en el cambio en la percepción de éstas, quienes cayeron continuamente en el "'yo nunca dije', 'no estaba dentro de mis facultades', 'mi investidura no me permitía decir eso'. Entonces, era nuestra palabra de lo que nosotros escuchábamos contra lo que ellos realmente dijeron. Se hicieron muchas promesas y nosotros confiamos, pero con el tiempo nos dimos cuenta que las autoridades no eran honorables. Confiamos en autoridades que se nos cayeron del pedestal, que no cumplieron lo que prometieron y desconocen todo, dando responsabilidades a terceros" (sic) (Tomás Pablo, entrevista, 26-X-2012). Los representantes

10 Tomás Pablo nació en Gualliguaica en 1970, viviendo en Gualliguaica durante toda su vida. En el proceso de erradicación participó en el Comité de Refundación de Gualliguaica en calidad de dirigente que representaba al Comité de Allegados del poblado. Actualmente se desempeña como auxiliar de la Escuela Amelia Barahona Mujica de Gualliguaica, y es un activo miembro del Comité de Aguas del pueblo. 
estatales también apelaron al olvido y a las supuestas limitaciones en sus cargos para no ejecutar una acción determinada. Según Tomás Pablo, antes "veíamos autoridades elegidas por el pueblo, personas honorables y respetuosas que cumplían lo que decían" (Tomás Pablo, entrevista, 26-X-2012). Sin embargo, éstas perdieron toda credibilidad a causa de las negligencias cometidas durante la erradicación y relocalización de Gualliguaica.

Por otra parte, se gestó la idea de que las autoridades regionales actuaron con irresponsabilidad al no informar al Gobierno Central cuestiones referentes a los poblados afectados. La falta de prolijidad quedó demostrada cuando las autoridades propusieron a los pobladores de Gualliguaica el pago de indemnizaciones como compensación a la erradicación, negándose al deseo de los gualliguaiquinos de que se les construyera un pueblo nuevo. Los dirigentes de Gualliguaica "hicieron carpetas registrando a las personas que vivían en el pueblo para apelar a otras instancias y hacer un pueblo nuevo. El Comité llegó hasta Santiago para conversar con Ricardo Lagos e informarle de las familias que se verían afectadas por la construcción, sorprendiéndose el otrora Ministro por la cantidad de potenciales damnificados porque, según información dada a él por sus mandos intermedios, la cantidad de gente afectada por el embalse era más bien baja, siendo fácil erradicarlas" (René Arias, entrevista, 4-X-2012). ¿Quiénes informaron al Ministro Lagos sobre el "escaso número" de afectados por el Puclaro? Sin duda, fueron las autoridades regionales que mantenían contacto directo con las autoridades de Santiago quienes comunicaron aquello, siendo responsables de dar cuenta al Gobierno Central del desarrollo del proceso. En consecuencia, tal y como señaló Tomás Pablo, "las autoridades de la región intentaban aplacar todo" (Tomás Pablo, entrevista, 26-X-2012).

En suma, las autoridades reiteraron que existió preocupación por los afectados del Puclaro desde un comienzo, pese a que no fuese una obligación legal. Sin embargo, los pobladores y sus dirigentes contradijeron la versión de las autoridades, generándose interrogantes respecto al devenir de las comunidades cuando el embalse comenzó a construirse. La improvisación, las promesas incumplidas y el olvido de las autoridades durante este período deterioraron la percepción que tenían los pobladores sobre ellas.

\section{La unión hace la fuerza}

Volviendo al relato de la visita de dirigentes vecinales a Ricardo Lagos a Santiago, hay un elemento que no ha sido desarrollado: la existencia de un Comité. De esta forma, surgen nuevas preguntas: ¿en qué consistió y quiénes conformaron este Comité? ¿Esta agrupación canalizó la acción colectiva del pueblo de Gualliguaica? ¿La organización de este Comité demostró que hubo respuestas de los pobladores a la erradicación y relocalización forzadas? 
La Polvada fue uno de los poblados afectados por la construcción del embalse que se opuso a gran parte de las propuestas de relocalización, no logrando establecer un diálogo fructífero con las autoridades. Desde que los representantes estatales se preocuparon por la erradicación, les propusieron a los vecinos de dicho sector distintas alternativas de relocalización. Primero, se les ofreció reubicarse en Gualliguaica, luego en Vicuña y, finalmente, en El Tambo. Sin embargo, rechazaron tales opciones, aceptando finalmente, en 1999, irse a una villa que agruparía a los pobladores de La Polvada y Punta Azul. Las sucesivas negativas en La Polvada demuestran que no existió un diálogo directo ni fructífero entre sus habitantes y las autoridades regionales. De haber ocurrido lo contrario, el poblado habría decidido dónde y cómo sería relocalizado antes de 1999. Incluso, vecinos de dicho poblado acusaron que las autoridades los discriminaron, ya que algunos de ellos no recibieron subsidios para las viviendas de la nueva Villa Puclaro (Diario El Día, 6-XII-2000). La firme creencia de que el Embalse Puclaro no se construiría, gatilló la tardía reacción de los pobladores ante una situación cada vez más apremiante. René Arias, Director de la Escuela de Gualliguaica, señaló que "se quiso incorporar a los poblados de Punta Azul y La Polvada al Comité de Refundación de Gualliguaica, pero ellos no quisieron porque nunca creyeron" (René Arias, entrevista, 4-X-2012). Otra causa de la respuesta pasiva y poco productiva de los pobladores de La Polvada fue la gestión de sus dirigentes, pues "los pocos actores sociales que estaban generando acciones de movilización, fueron mujeres dirigentes vecinales que no encontraron el apoyo suficiente para llevar a cabo sus iniciativas de interacción social y desarrollo" (Gómez, 2009: 165). Por tanto, la escasez de ayuda fue otro aspecto clave que determinó el futuro de La Polvada.

Sin embargo, ¿este apoyo debió provenir sólo de las autoridades o también de gente relacionada al pueblo? ¿Por qué no fue creada una agrupación dentro de La Polvada que influyera en las decisiones de las autoridades a través de un accionar colectivo organizado? Para dilucidar estas cuestiones, debe conocerse la respuesta de Gualliguaica ante el proceso de construcción del Puclaro.

Las dudas persistieron antes de que Gualliguaica se organizara, expresándose dicha incertidumbre en manifestaciones públicas de rotundo rechazo al embalse. Cuando se supo que el embalse se construiría, las primeras reacciones en Gualliguaica fueron de duda, inconformidad y desesperación, ya que se desconocían soluciones concretas para hacer frente a la inminente inundación del pueblo. Por esta razón, existió un rechazo rotundo a la obra, instalándose "grandes letreros, como uno en la ladera del cerro que decía 'No al tranque'"; también "hubo manifestaciones cuando se hicieron las primeras incursiones y se instaló la primera piedra" (René Arias, entrevista, 4-X-2012). Además, se crearon "pancartas, un mural natural en la línea del 
tren; se hacían protestas con carteles, banderas negras y con los niños gritando 'No al tranque'" (René Arias, entrevista, 4-X-2012). Tomás Pablo relató un episodio que demostró tal desaprobación categórica: "Un día vino Eduardo Frei al embalse para colocar la primera piedra, y vinieron las autoridades a pedir que los niños de Gualliguaica vayan a hacerse presentes al acto y canten el himno nacional. El profesor [René Arias] dice que no, porque no iba a llevar a los hijos de personas que iban a perderlo todo, o que están en desacuerdo con la obra [...] Por lo que llama a algunos apoderados y estos retiran a los niños de la escuela. Finalmente, los niños terminan yendo, pero van a manifestarse en contra de la obra" (Tomás Pablo, entrevista, 26-X2012). Pese a que también hubo intentos de bloqueos de caminos como expresión de rechazo a la obra, éstos no se concretaron. Ante el estado de duda, inseguridad y oposición vivido en este poblado, una persona arribó al pueblo y cambió el accionar colectivo de Gualliguaica ante la erradicación: Marcelo Olivares.

Gracias a la labor de Marcelo Olivares, Gualliguaica consolidó una firme y organizada acción colectiva, arribando con un discurso que instaba a abandonar las manifestaciones y organizarse, creándose el Comité de Refundación de Gualliguaica. Marcelo Olivares fue miembro del CORE (Consejo Regional) y estaba vinculado a Gualliguaica por su descendencia familiar. Gracias a su cargo político, "él estaba ahí, donde las personas estaban tomando las decisiones, teniendo contactos e informaciones relevantes" (Tomás Pablo, entrevista, 26-X2012). Olivares llegó al pueblo con otra forma de visualizar el problema y con nuevas respuestas ante la erradicación. Este dirigente le dijo a los gualliguaiquinos que "cómo íbamos a tratar de parar la construcción del embalse si ya se estaba construyendo, no sería fácil detenerla. Nosotros debíamos preocuparnos de nosotros, de ver las formas para salir de esta crisis de la mejor manera posible" (Tomás Pablo, entrevista, 26-X-2012). La propuesta de Olivares consistió en "organizarse, golpear puertas y ver la forma de salir bien parados de este proceso. Esto haría aunar fuerzas, ver lo que podíamos obtener y cuánto nos ofrecía la autoridad" (Tomás Pablo, entrevista, 26-X-2012). Para congregar a los pobladores y pensar en las futuras directrices del proceso, se creó el Comité de Refundación de Gualliguaica, agrupación encabezada por Marcelo Olivares que reunió a instituciones del poblado como la Junta de Vecinos, Comité de Allegados, Club Deportivo, Centro de Padres, Dirección de la Escuela y Comité Católico. El Comité de Refundación nació gracias al profundo deseo que tenían los gualliguaiquinos: vivir juntos en un nuevo pueblo que estuviese ubicado cerca del antiguo que sería inundado por las aguas.

Permanecer unidos fue otra razón para que Gualliguaica dejara de lado las manifestaciones, tuviese una buena relación con las autoridades y aumentara su cohesión social. Violeta Cáceres, Presidenta de la Junta de Vecinos de Gualliguaica durante la erradicación, señaló que "cuando hacíamos reunio- 
nes no faltaban dos o tres pobladores que empezaban a 'tirar dardos' a las autoridades. Entonces, ¿qué hacían ellas? Se paraban y no dejaban nada. Una vez nosotros dijimos: 'Tenemos que dialogar, tenemos que conseguir algo bueno. Por ejemplo, que las indemnizaciones sean buenas y que nos den una casa digna'" (Violeta Cáceres, entrevista, 27-X-2012).

Además de detener las manifestaciones que entorpecieran el diálogo con las autoridades, se buscó mantener una relación fluida con ellas, pues era el único camino válido para conseguir la construcción de un nuevo pueblo. Para Tomás Pablo, el accionar colectivo más adecuado era "tomar una actitud cercana con las autoridades" (Tomás Pablo, entrevista, 26-X-2012). Esta buena relación fue destacada durante el acto de colocación de la primera piedra del nuevo pueblo de Gualliguaica, instancia en la que el Ministro de Obras Públicas Jaime Tohá resaltó "la manera tan armónica como se han resuelto los problemas sociales" (Diario El Día, 22-III-1999). Un fruto de la unión del poblado fue el aumento de la cohesión social, reflejada en la convocatoria a las reuniones y asambleas para discutir temas referentes al embalse. En 1996, Violeta Cáceres señaló que en dichas instancias "eran pocos los asistentes; ahora, en cambio, que veían que todo avanza, llegaron más de cien a cada asamblea" (Diario El Día, 3-VI1996). También hubo un aumento de la participación colectiva en actividades comunitarias, ya que se "fortalecieron las instituciones que estaban dormidas cuando se empezó a construir el tranque. La gente se cohesionó, se reunió, comenzó a funcionar mejor la Junta de Vecinos, el Club Deportivo, el Comité Religioso. Las fiestas religiosas fueron las más grandes de la historia del pueblo porque eran las últimas. Incluso volvió gente que se había ido hace años de Gualliguaica y estuvo aquí" (René Arias, entrevista, 4-X-2012).

Por último, otro factor que aumentó la cohesión social fue el apoyo de la Iglesia, del Arzobispado y del "Párroco Fidel", quienes participaron en las asambleas, ayudaron espiritualmente a los pobladores que, en su mayoría, eran católicos, y organizaron actividades religiosas como "El Éxodo", instancia en la que se retiraron las imágenes de la capilla del pueblo antiguo.

En síntesis, las personas de La Polvada no lograron un diálogo productivo con las autoridades, a causa de la gestión de sus dirigentes y de la creencia que el embalse no se construiría. Por ello, en este poblado fueron rechazadas las propuestas de los representantes regionales. Mientras que en Gualliguaica abandonaron las manifestaciones y se agruparon en torno al Comité de Refundación. La gestión de Marcelo Olivares fue clave para los gualliguaiquinos, fomentándose las buenas relaciones con las autoridades, la unión del pueblo para luchar por un objetivo común y la cohesión social. En consecuencia, se plantea la existencia de dos tipos de respuesta de la población local ante la construcción del Puclaro: una pasiva -hecha en La Polvada- y otra activa -experiencia de Gualliguaica. 


\section{Nada iba a ser como antes}

Las respuestas de La Polvada y Gualliguaica ante la construcción del embalse y el proceso de erradicación fueron diferentes. En efecto, cabe preguntarse: ¿en qué medida tales respuestas influyeron en las compensaciones que los poblados recibieron? ¿Estuvieron relacionadas las respuestas hechas ante el Puclaro y la magnitud de los problemas sufridos durante el desarrollo de la obra? Pese a la acción colectiva y sus resultados, ¿ambos poblados sufrieron graves problemas durante el período investigado?

La Polvada padeció mayores problemas y obtuvo menores compensaciones que Gualliguaica durante la construcción del Puclaro. A lo largo de este período, los primeros sufrieron tronaduras; definieron tardíamente dónde serían reubicados; fueron trasladados a viviendas provisorias; padecieron los efectos de la contaminación, daño psicológico, y retrasos en la entrega de las casas definitivas; y estuvieron disconformes por las dimensiones de los terrenos y viviendas, y por las características del nuevo poblado.

Sucesivas tronaduras por las obras de reconstrucción de la Ruta D-41 fueron producidas durante 1997, las cuales afectaron a quienes vivían en La Polvada y provocaron respuestas legales. Estas tronaduras "se produjeron a toda hora del día, cayendo gigantescas rocas en las inmediaciones de las casas" (Diario El Día, 24-IV-1997). El problema de Raquel Traslaviña, perteneciente a este poblado, era que "tengo la casa llena de piedras, lo que ha significado que ésta se encontrase prácticamente demolida" (Diario El Día, 24-IV-1997). Para la señora Traslaviña era preocupante "la inseguridad en que vivíamos porque a diario y en cualquier momento nos caían piedras desde el cerro, lo que convierte nuestra vida en un infierno, dada la permanente inseguridad y temor que provoca" (Diario El Día, 24-IV-1997). A causa de este inconveniente, los pobladores interpusieron un Recurso de Protección en la Corte de Apelaciones de La Serena contra la empresa Fe Grande, por los daños y perjuicios sufridos en La Polvada (Diario El Día, 5-VI-1997). Sin embargo, la Corte rechazó este Recurso porque "no existieron actos ilegales y arbitrarios por la Empresa Constructora Fe Grande, dado que habría actuado conforme al contrato suscrito con el Ministro de Obras Públicas" (Diario El Día, 1-VIII-1997). Estas tronaduras provocaron daños psicológicos en las personas por el riesgo de sufrir perjuicios físicos e incluso morir, deteriorándose también las viviendas y los terrenos cultivados.

Los habitantes de La Polvada supieron dónde serían relocalizados definitivamente sólo meses antes de comenzarse a llenar el embalse, pues se negaron sucesivamente a las propuestas de las autoridades. Ellos fueron reubicados en viviendas provisorias al iniciarse el llenado del Puclaro, dadas las negativas a los ofrecimientos de traslados definitivos hechos por las autoridades regionales. Posteriormente, el Servicio de Vivienda y Urbanismo 
(SERVIU) propuso trasladar a las familias a Vicuña en 1999, lugar en el que sí era posible entregarles viviendas con las condiciones que se exigían ${ }^{11}$ (Diario El Día, 18-III-1999). Esta propuesta también fue rechazada al no ser aprobada unánimemente por los pobladores. Finalmente, no tuvieron otra alternativa que aceptar establecerse en un nuevo poblado en Punta Azul. Los pobladores de La Polvada supieron dónde serían reubicados en marzo de 1999, pese a que sólo unos meses más tarde -en octubre del mismo año- las compuertas del embalse fueron cerradas para acumular agua. Al ser inviable construir un nuevo poblado en siete meses, los habitantes de La Polvada fueron enviados a un campamento con mediaguas reforzadas y servicios de luz y agua potable, localizado en un cerro frente a Punta Azul (Diario El Día, 23-X-1999). Los habitantes de La Polvada ya sufrían otros problemas, tales como la falta de acceso a locomoción, la presencia de material en suspensión, el tránsito de gente que no era del lugar, y los ruidos de las máquinas que resquebrajaban la tranquilidad con la que antes se vivía (Diario El Día, 25-X-1999).

En marzo del 2000, fecha en que serían entregadas las viviendas a las personas de La Polvada, éstas aún no estaban terminadas, habiendo críticas y nuevos retrasos en la entrega definitiva del nuevo poblado. Tres de los habitantes más longevos de La Polvada fallecieron dentro del campamento provisorio en septiembre del 2000 (Diario El Día, 5-IX-2000). Sumado al retraso, hubo malestar por el tipo de vivienda que se estaba construyendo, siendo "una casita con tres metros de antejardín y 9 metros de fondo", de "treinta y seis metros cuadrados; mientras que ellos vivían en casas de cien y ciento veinte metros cuadrados" (Diario El Día, 6-XII-2000). Otras preocupaciones de los pobladores fueron los riesgos potenciales de aluviones o bajadas de quebradas, y la falta de pavimentación y cierre perimetral de cada sitio. Incluso, los retrasos se prolongaron durante el 2001, pues, en marzo de ese año, surgieron problemas con la estructura arquitectónica del poblado, requiriéndose estudios y mayores recursos para mitigar efectos negativos (Diario El Día, 6-III-2001).

Al revisar las dificultades que sufrieron los habitantes de La Polvada cabe preguntarse si el progreso de que tanto hablaron las autoridades regionales y nacionales responsables de la construcción del embalse también llegó a dichos pobladores. En suma, en vez de beneficiarse por el progreso, las personas de La Polvada debieron pagar el costo de dicho progreso. Por otra parte, si bien Gualliguaica también sufrió las externalidades negativas del Puclaro, mitigó un poco más los efectos de la construcción del embalse.

El proceso de los gualliguaiquinos no fue totalmente similar al vivido en La Polvada, pues no sufrieron tronaduras ni contaminación del ambiente, no

11 Las condiciones que exigían era obtener casas individuales y no pareadas, con una superficie total de 300 metros cuadrados. 
debieron trasladarse a viviendas provisorias, y acordaron la construcción de un nuevo pueblo con antelación. La exención del problema de la contaminación del aire producto de las obras del Puclaro, de la Ruta D-41, y de la extracción de áridos, se debió a que Gualliguaica estaba más distante de la construcción que La Polvada y Punta Azul. Además, la empresa que construyó el embalse solo podía efectuar trabajos de extracción de áridos hasta 3 kilómetros del muro de la obra (René Arias, entrevista, 4-X-2012). A fines de 1996, el Intendente de la Región de Coquimbo Renán Fuentealba confirmó que se construiría un nuevo pueblo de Gualliguaica (Diario El Día, 14-XI-1996); por tanto, ya existía certeza de que se construiría un nuevo pueblo a tres años de que operase el Puclaro, evitando que las autoridades crearan planes alternativos y urgentes como los hechos para La Polvada. Tampoco los gualliguaiquinos fueron trasladados a viviendas provisorias como el campamento para las personas de La Polvada, a causa de que la edificación del nuevo Gualliguaica ya estaba concluida cuando las aguas del Puclaro inundaron completamente al antiguo poblado. Por otra parte, las personas de Gualliguaica recibieron mayores compensaciones que sus homólogos de La Polvada.

Los gualliguaiquinos obtuvieron mayores beneficios que los habitantes de La Polvada, tales como mejores condiciones de las viviendas definitivas, mayor superficie de los terrenos y características superiores del nuevo pueblo de Gualliguaica. Pese a que los metros cuadrados de las viviendas de ambos poblados fueron similares -35 y 36 metros cuadrados-, las casas de Gualliguaica fueron entregadas con un comedor, un baño, cocina y un dormitorio, junto con sistema de alcantarillado y electricidad. También hubo diferencias en las superficies totales de los terrenos, ya que los 600 metros cuadrados de una propiedad de Gualliguaica distaron de los 108 metros cuadrados de cada sitio en Villa Puclaro. Hubo diferencias más evidentes en las características de cada poblado, pues el nuevo Gualliguaica sólo integró a personas que vivían en el antiguo Gualliguaica, mientras que Villa Puclaro agrupó a pobladores de La Polvada y Punta Azul. Asimismo, la iglesia y la estación de ferrocarriles del antiguo pueblo de Gualliguaica fueron reconstruidas porque eran símbolos históricos y culturales de la identidad gualliguaiquina. Junto a estas edificaciones, en el nuevo pueblo gualliguaiquino se construyeron un centro médico rural, una nueva escuela y una variante caminera que comunicase al pueblo con la Ruta D-41. Sin embargo, pese a que Gualliguaica evitó algunos inconvenientes y recibió mayores compensaciones, presentó similitudes con La Polvada en cuanto a los problemas que sufrieron a causa del Puclaro.

Entre los problemas que sufrieron tanto los habitantes de la Polvada como los de Gualliguaica se encontraron daños psicológicos, pérdidas de vidas humanas, reducción de la superficie de los terrenos de sus habitantes y elementos inconclusos de los nuevos poblados. El Hospital de Vicuña realizó un estudio de salud mental a algunos vecinos de Gualliguaica en 
1997, evidenciándose daño psicológico por la presencia de altos niveles de alcoholismo en los hombres, y ansiedad y depresión en las mujeres (Diario El Día, 7-Xl-1997). También la población de La Polvada sufrió daño psicológico, a causa de las obras del embalse, de las tronaduras que sucedían en cualquier momento y del arribo de personas extrañas que rondaban por la zona. El perjuicio psicológico fue más profundo en los adultos mayores; la erradicación y la nueva vida en los poblados significó un duro golpe para ellos. Al igual que las muertes de algunos habitantes de La Polvada ocurridas en el campamento provisorio, Elisa y Rafael Codoceo, Julita Ocaranza, Luis Flores y otros vecinos del antiguo poblado fallecieron en Gualliguaica. Según Violeta Cáceres, ellos "se fueron de este mundo con mucha pena porque no soportaron el cambio. Don Rafael Codoceo nunca asumió que debían cambiarse, por lo que dijo que iba a morirse de pena. A Julita Ocaranza también le pasó lo mismo porque no quería cambiarse. Todas esas personas murieron con una pena enorme porque alcanzaron a vivir muy poco tiempo en el pueblo nuevo, estando con toda la pena del traslado." (sic) (Violeta Cáceres, entrevista, 27-X-2012). Por otra parte, los gualliguaiquinos sufrieron la reducción de las superficies de sus terrenos. Si antes éstos eran de una o dos hectáreas, luego disminuyeron a 600 metros cuadrados, implicando el término de las faenas agrícolas domésticas. Tal y como ocurrió en Villa Puclaro y la escuela que no se construyó, en Gualliguaica tampoco se edificaron la plaza y la pavimentación completa del poblado; tampoco se entregaron acciones de agua que, hasta hoy, impiden el aprovisionamiento hídrico seguro y permanente para los gualliguaiquinos.

En páginas anteriores quedó demostrado que La Polvada fue más perjudicada que Gualliguaica durante los procesos de construcción del embalse, erradicación y relocalización, producto de sus desventajas geográficas y de la respuesta tardía y poco activa ante la edificación del Puclaro. Si bien Gualliguaica presentó una respuesta más anticipada, organizada y clara, y recibió un nuevo poblado con mayor antelación y mejores condiciones, también debió superar problemas asociados a la erradicación como el daño psicológico, fallecimiento de personas, reducción de dimensiones de las propiedades y falta de infraestructura en el poblado. Esto provocó que los gualliguaiquinos también sufrieran los efectos negativos del desarraigo y del abandono de las actividades agrícolas a pequeña escala.

En síntesis, los habitantes de La Polvada sufrieron mayores dificultades que los gualliguaiquinos durante el período investigado, tales como tronaduras, contaminación ambiental, y reubicación temporal. Además, existió disconformidad por los retrasos en los trabajos y por las características de la nueva Villa Puclaro. Si bien en Gualliguaica se supo con antelación que sería construido un nuevo poblado y no sufrieron tronaduras ni contaminación, también fueron afectados por la reducción de las dimensiones de los terrenos, sufriéndose daño psicológico y lamentándose fallecimientos. En consecuencia, pese a que los 
gualliguaiquinos recibieron mayores compensaciones que los pobladores de La Polvada, ambos sufrieron graves problemas por la construcción del embalse.

\section{Conclusión: ¿Qué ha dejado este proceso?}

Nuestro país ha dependido históricamente de actividades económicas primarias como la agricultura. La agroindustria de exportación ha sido potenciada gracias al arribo de inversiones naciones e internacionales, las cuales han aprovechado las ventajas comparativas de Chile para obtener importantes dividendos económicos. En el Norte Chico, el Valle del Elqui ha sido un polo atractivo para el cultivo de la uva de exportación, entre otros productos. Dada la limitación de la disponibilidad de recursos hídricos para sostener la expansión exportadora, se han construido embalses que han representado seguridad y gestión eficaz del agua. Sin embargo, estas obras de irrigación han provocado problemas profundos a sociedades locales. Esta investigación estudió el proceso de construcción del Embalse Puclaro en una zona favorable para el desarrollo agrícola comercial. Durante ese período, se desarrolló un conflicto reflejado en los discursos de las autoridades y de los pobladores afectados por el Puclaro. Ante la construcción del embalse, los poblados respondieron a través de distintas formas de acción colectiva: una pasiva que careció de claridad y organización, hecha en La Polvada; y otra activa y organizada, efectuada en Gualliguaica. Pese a que las compensaciones recibidas por ambos poblados reflejaron las acciones colectivas ante la construcción del Puclaro, las personas de ambas localidades sufrieron problemas similares durante los procesos de erradicación y relocalización.

¿Cuáles han sido las implicancias y los efectos de este proceso durante la elaboración de la presente investigación? Para responder esto, la atención se centra en Gualliguaica. En primer lugar, la cohesión social de la comunidad ha cambiado. Una vez que las personas se instalaron en el nuevo Gualliguaica, el fuerte vínculo social creado durante el proceso de erradicación se desintegró, debido a que iniciaron una vida desde cero. Los gualliguaiquinos debieron trabajar arduamente para cultivar sus nuevos huertos y ampliar sus casas, no disponiendo de tiempo suficiente para interactuar con sus vecinos. Sin embargo, a once años de inaugurado el nuevo pueblo de Gualliguaica, se ve una mayor participación de la comunidad en asociaciones como el Club de Huasos o el Grupo Folclórico. Pese a perderse la cohesión social lograda durante el proceso de erradicación, el pueblo nuevo de Gualliguaica está mucho mejor en comparación al momento en el que arribaron a él, a causa de los trabajos que cada familia ha hecho por su propia cuenta en sus propiedades. Ahora bien, ¿siguen habiendo asuntos inconclusos?

Hay problemas que no han sido solucionados, tales como la ausencia de la plaza y de acciones de agua, las cuales son promesas incumplidas por 
las autoridades e impedimentos para que Gualliguaica prospere. La plaza de Gualliguaica es uno de los asuntos sin concretar, requiriéndose como elemento para cohesionar al poblado. La falta de acciones de agua es otra dificultad seria, pues los gualliguaiquinos han recibido agua potable gracias a particulares que viven en zonas aledañas y donan el recurso hídrico. Esta situación es inexplicable y paradójica: inexplicable, pues el otorgamiento de acciones de agua fue una promesa incumplida de Mirtha Meléndez, Directora Regional de Obras Hidráulicas durante el proceso de construcción del embalse; y paradójica, ya que un poblado que debió ser reubicado por la construcción de un embalse, no tiene actualmente un aprovisionamiento seguro de agua. Así, las promesas incumplidas reflejan la falta de apoyo de las autoridades. Una vez que el nuevo pueblo de Gualliguaica fue inaugurado, los representantes estatales se olvidaron de los pobladores y de los compromisos que sostuvieron a lo largo del período investigado.

Otra situación preocupante es el descenso del nivel de las aguas acumuladas del Puclaro, anomalía que ha repercutido en el arraigo de los gualliguaiquinos con el antiguo poblado inundado la década anterior. El volumen de agua acumulada por el Embalse Puclaro ha disminuido notoriamente desde el año 2008. Este descenso ha dejado al descubierto el antiguo pueblo de Gualliguaica, contemplándose incluso las delimitaciones de cada uno de los terrenos, los troncos de algunos árboles que fueron arrasados por las aguas y las bases de concreto de algunas viviendas. Esto ha avivado el arraigo de las personas con el antiguo poblado, lugar donde se criaron, forjaron sus anécdotas de infancia, estudiaron y formaron una familia. Recorrer el pueblo antiguo ha permitido a los pobladores rencontrarse con su tierra, habiéndose realizado actividades como una liturgia celebrada en el sitio donde se encontraba la iglesia antigua, evento al cual asistió gran parte de la comunidad gualliguaiquina (Tomás Pablo, entrevista, 26-X-2012).

Pese al arraigo que las personas adultas sienten por el pueblo antiguo, las generaciones más jóvenes experimentan una situación distinta. Estas últimas no sufrieron el proceso de erradicación al haber sido personas de baja edad en ese entonces -incluso algunas aún no nacían-. En efecto, las generaciones jóvenes sienten un mayor vínculo con el nuevo poblado que las personas mayores, descubriendo más aspectos positivos de la nueva locación. Emilia Cok, joven gualliguaiquina, dijo el año 2012 que "sí, me gusta [el pueblo nuevo]. En el antiguo yo estaba más alejada de la gente, y acá estoy más cerca y tengo más comunicación con los demás. Abajo [en el pueblo antiguo] no teníamos electricidad en la casa y acá sí. Vemos más televisión y es más cómodo. Es mejor esto que el pueblo de abajo" (Emilia Cok, testimonio en reportaje audiovisual, 21-X-2012). De este modo, las generaciones más jóvenes son las llamadas a "echar raíces" en el poblado, a quererlo y protegerlo; pues en el nuevo Gualliguaica conviven a diario con sus pares y están creando sus recuerdos de infancia imperecederos, tal y como lo hicieron sus 
padres en el pueblo antiguo. Se espera que ellos sean el futuro del poblado, haciéndolo prosperar y queriéndolo más que sus padres y abuelos, quienes no sienten tan propio el nuevo Gualliguaica.

Figura 1 Poblado de Gualliguaica antes de ser inundado por las aguas del Puclaro.

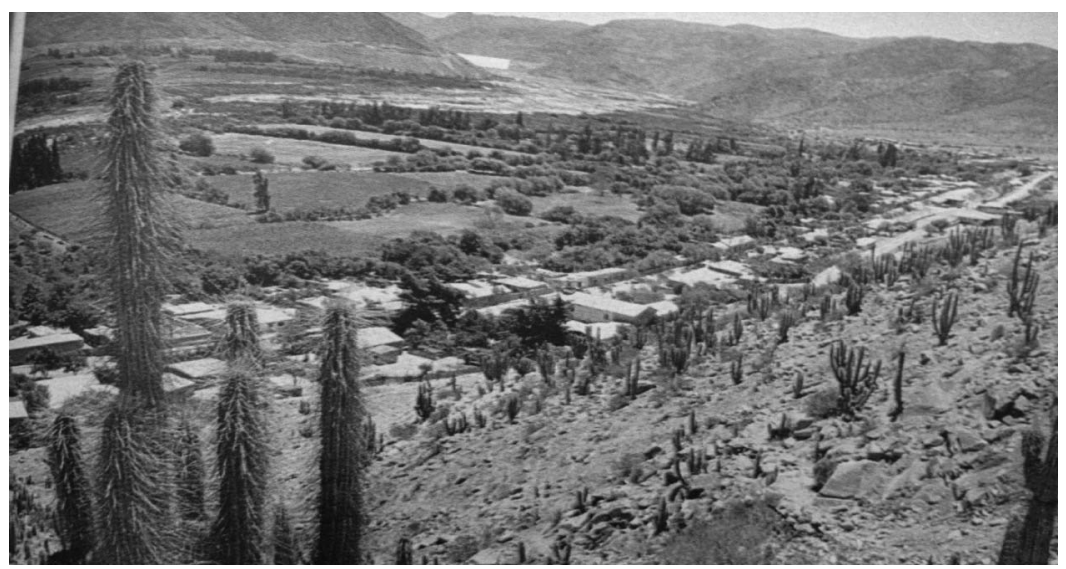

Fuente: Diario El Día, 30-X-1999.

Figura 2 Restos del antiguo poblado de Gualliguaica luego del descenso de las aguas del Puclaro

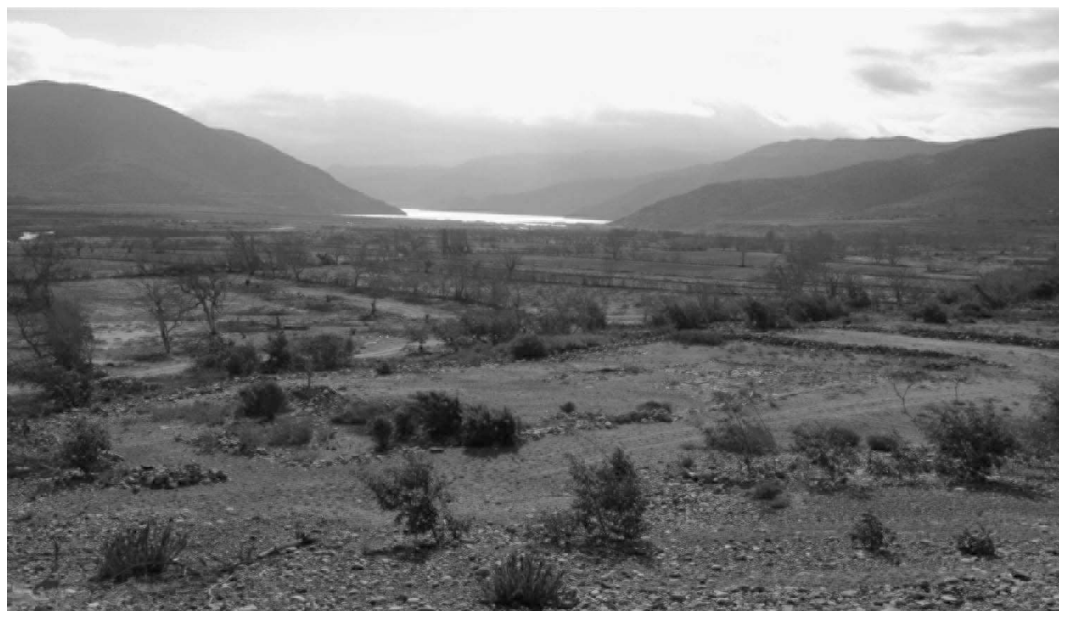

Fuente: Registro personal, 20-VII-2012.

Luego de todo lo escrito es pertinente preguntarse: ¿llegó el progreso a las personas afectadas por la erradicación forzada derivada de una política pública? ¿El progreso, en caso de haber llegado, fue el mismo que el obtenido por los grandes ganadores por la construcción del Puclaro, es decir, los grandes 
empresarios y agricultores con capital suficiente para invertir en cultivos como la uva de exportación? ¿Las autoridades dimensionaron el impacto de esta construcción que, incluso, cobró vidas humanas? Este caso de estudio refleja una sociedad local con dos grupos. En primer lugar, existe una minoría con limitadas herramientas económicas, sociales y políticas, la cual absorbe las externalidades negativas de una obra. Mientras que en segundo lugar, hay otra minoría con influencias económicas y políticas que es favorecida por una política pública, camuflándose como mayoría para legitimar la construcción de una obra que le generará importantes dividendos económicos, absorbiendo así las externalidades positivas de una gran infraestructura como un embalse.

De este caso de estudio también se desprende que las personas afectadas por la aplicación de una política pública pueden actuar colectivamente para establecer un diálogo directo y detener conflictos con representantes estatales. La acción colectiva gualliguaiquina ilustra esta situación, la cual fue gestada por tres factores: la labor de dirigentes locales que encauzaron a sus coterráneos, la cohesión social para que todos trabajasen en pos de un solo objetivo y el fuerte arraigo con la tierra de la que provenían. Este sentido de pertenencia fue un estímulo para defender lo que más amaban: el lugar donde nacieron, crecieron y descansan sus antepasados.

El mensaje final es de estímulo a conocer y desarrollar investigaciones sobre historia ambiental. Éste es un campo reciente en la historiografía chilena y latinoamericana que ha permitido elaborar nuevas preguntas y hallar novedosas respuestas acerca del hombre y el ambiente. Si adoptamos la premisa de que las acciones humanas han dejado huellas imborrables en los ecosistemas que han sido descubiertos y conquistados, el estudio de los rastros encontrados en el medioambiente debe cumplir uno de los objetivos elementales de la Historia como disciplina: ayudar a comprender el presente y prepararnos para no cometer los mismos errores del pasado en el futuro; vale decir, "Historia magistra vitae est".

\section{Referencias bibliográficas}

\section{Fuentes Primarias}

\section{a. Impresos}

Comisión Nacional de Riego (1999). Chile Riego. Santiago, Chile, 1: Ministerio de Agricultura.

Ministerio de Obras Públicas (2001). Gualliguaica: Primer Pueblo del Siglo XXI. Santiago, Chile: Ministerio de Obras Públicas. 


\section{b. Prensa periódica}

Diario El Día, La Serena, 1996-2001.

\section{c. Entrevistas y testimonios}

Arias, René, entrevista, 4-X-2012.

Cáceres, Violeta, entrevista, 27-X-2012.

Pablo, Tomás, entrevista, 26-X-2012.

Cok, Emilia, testimonio en reportaje audiovisual "La historia reflotada", programa de televisión "Tele 13", Chile, 21-X-2012.

\section{Fuentes Secundarias}

\section{a. Artículos}

Gallini, S. (2009). "Historia, ambiente, política: el camino de la historia ambiental en América Latina", en Revista Nómadas, №30, Universidad Central, Colombia, pp. 92-102.

Gómez, G. (2009). "Proceso de mutación cultural desde experiencias cotidianas en Villa Puclaro", en Revista INVI, Vol. XXIV, №66, Santiago: Facultad de Arquitectura y Urbanismo Universidad de Chile, pp. 159-190.

Murray, W. (1999). "La globalización de la fruta, los cambios locales y el desigual desarrollo rural en América Latina: Un análisis crítico del complejo de exportación de fruta chilena", en EURE, Vol. XXV, №75, Santiago, pp. 77-102.

\section{b. Libros}

Benz, V. (1997). Gualliguaica: Donde el agua rompe el cielo, Antofagasta: Ediciones Universitarias Universidad Católica del Norte.

Cereceda, L. (1980). Dos décadas de cambios en el agro chileno, Santiago: Instituto de Sociología, Pontificia Universidad Católica de Chile.

Gómez, S. y Echeñique J. (1988). La agricultura chilena: las dos caras de la modernización, Santiago: FLACSCO.

Santana, R. (2006). Agricultura chilena en el siglo XX: contextos, autores y espacios agrícolas, Santiago: Centro de Investigaciones Diego Barros Arana.

\section{c. Otros}

EL OBSERVATODO, "Inauguran Central Hidroeléctrica Puclaro: abastecerá a 12 mil hogares de la región", en http://www.elobservatodo.cl/admin/render/noticia/10408 (visitado el 24 de octubre de 2012). 